\title{
APLICACION A LAS CORPORACIONES LOCALES DE OPERACIONES DEL TESORO
}

La Hacienda Estatal realiza dos clases de operaciones: Operacionec del Presupuesto y Operaciones del Tesoro. Las primeras responden a los gastos públicos y a los recursos necesarios para atenderlos, las segundas a las operaciones de Tesorería y Bancarias, consecuencia de las primeras. Estas operaciones son de tal necesidad al desarrollo de las actividades financieras del Estado que sin ellas sería imposible atender a los múltiple6 servicios que tiene a su cargo el Ministerio de Hacienda; de ahí que exista una Dirección General exclusivamente encargada de este servicio, la Dirección General del Tesoro.

¿Es posible aplicar a las Haciendas Locales estas operaciones? Dejando aparte los Depósitos por ser operación corriente y normal en las Corporaciones locales y los Giros y Valores y Movimientos de Fondos por ser propio de Haciendas ramificadas, las operaciones que interesan a nuestro estudio son: Deudores al Tesoro y Acreedores del Tesoro.

Deudores al Tesoro.-Constituyen estas operaciones los anticipos a reembolsar. Estos anticipos no son verdaderos créditos en el sentido juridico, ya que esta operación la sido prohibida por el artículo 4I de la Ley de Administración y Contabilidad de $\mathrm{I}^{\circ}$ de julio de $19 \mathrm{I}$, quedando reducida la autorización concedida por el artículo $90^{\circ}$ de la Ley de Presupuestos de 19 de mavo de 1870 , a aquellos pagos que por conveniencias de Contabilidad tienen aplicación provisional independiente del Presupuesto. Es indudable que las Corporaciones locales a semejanza del Estado pueden realizar tales operaciones, ya que las leyes de carácter financiero son aplicables a estas Eintidades con la debida adaptación. Ahora bien, ¿ én qué momento siente la necesidad la Hacienda local de realizar estas operaciones? Existen múltiples ocasiones en que tal realidad se presenta; supongamos la ejecución de fa!los de Tribunales, el caso de una calamidad pública de alguna importancia, la realización de plazos de deudas contraidas en firme por la Corporación, Presupuestos extraordinarios aprobados en espera de dota980 ción definitiva. etc., etc. En todos estos casos es de todo punto imposible 
esperar a la aprobación de la habilitación de créditos, a la aprobación del nuevo presupuesto o a la inclusión de la dotación pertinente, ya que con ello sufriría el prestigio y el crédito de las Autoridades y Representaciones locales. Se impone, por tanto, la realización de un anicipo a reembolsar, para lo cual habrá que atender al importe de la obligación y al estado de Tesorería de la Entidad que lo realiza. Estimamos que el estado de Tesorería es bueno, cuando la existencia en Caja es aproximadamente el doble de las obligaciones corrientes de una mensualidad; en cuanto al importe de las obligaciones a anticipar no deben ser superiores a la cuarta parte de aquella existencia. Una vez que la habilitación de créditos esté aprobada, confeccionado el Presupuesto o practicada la dotación correspondiente, se reembolsará el anticipo practicado con cargo a los créditos ap-obados. Debe preceder acuendo de la Corporación con informe del Interventor, haciendo constar tales extremos.

No se trata de habilitar gastos sin crédito suficiente al margen del artículo 303 del Estatuto Municipal, ni expedir libramientos en suspenso desconociendo el apartado c) del artículo 90 del Reglamento de Hacienda; es, sencillamente, anticipar unos fondos cuando concurren dos circunstancias esenciales reconocidas en el acuerdo pertinente: La apremiante obligación de disponer de fondos para atenciones cuya consignación en habilitaciones o presupuestos futuros no puede ser discutida por su carácter exigible y la existencia de una Tesorería floreciente que permita realizar la operación sin detrimento de las atenciones normales. Acaso parezca atrevido el procedimiento, dada la idiosincrasia de las Corporaciones locales españolas; pero téngase en cuenta que cuando la mecesidad se presenta es casi imposible soslayarla y al querer buscar solución se cae, con frecuencia, en ilegalidades tanto más perjudiciales cuanto más se abusa de ellas. No es descubrir ningún secreto al proclamar la existencia de aigunas Depositarías de fondos en las cuales hay que computar con metálico en Caja numerosas cuentas, liquidaciones, facturas, nóminas y listas de jornales. Para evitar transgresiones de la Ley, otras Corporaciones acuden a la pé ición de créditos bancarios, con lo cual se da la paradoja de que teniendo dinero en abundnncia en las Arcas Locales se pagan cuantiosris intereses al pedir dinero ajeno.

El registrar estas operaciones en Contabilidad no tiene dificultad alguna. Se abrirán dos cuentas, una en Gastos, capítulo Fondos Independientes del Presupuesto, artículo Operaciones del Tesoro, concepto Anticipos; y olira en Ingresos, el mismo capitulo y antículo, concepto Reembolsos. Al conceder el anticipo, se expedirá un libramiento con cargo al expresado capítulo, artículo y concepto, y al ser aprobado el gasto pertinente se hará una operación en formalización, expidiendo un cargaréme 981 
con cargo al capítulo, artículo y concepto indicados y un libramiento con cargo a los créditos aprobados. La cuen'a Anticipos es de pasivo, se datará de las cantidades a antic:par y se encargará de los pagos verificados como contrapartida del libramiento sentado en el Diario de Intervención de Pagos, columna Fondos Independientes del Presupues'o. La cuenta Reembolsos es de activo, se cargará de las cantidades a recmbo'sar por aprobación de las habilitaciones o presupuestos correspondientes y se datará de los ingresos verificados como contrapartida del cargaréme sentado en el Diario de Intervenc:ón de Ingresos; columna Fondos Independientes del Presupuesto. Si las operaciones fueran numerosas se abrirá un Auxiliar a las diferentes partidas o deudores cuyo cargo será el cargo de la cuenta de anticipos y cuya data, la data de la cuenta de Reembolsos.

Acreedores del Tesoro.-Estas operaciones están constituídas por los préstamos a devolver. Es operación contraria a la anterior, procede cuando la Tesorer'a de la Corporación en vez de ser floreciente es precaria, impidiendo atender a las más peren ${ }^{2}$ orias necesidades presupuestarias. La regula con todo detaile el apar!ado $b$ ) del art. 65 y el art. 66 del Reglamento de Hacienda, de erminando la cuantía máxima del crédito, el plazo de concesión, la necesidad del informe del Interventor y el acuerdo de la Corporación: en pleno.

Se trata de dar soluc:ón a un déficit momentáneo de Tesorería, es decir, la situación ror la cual las ex:gibilidades so presentan, en aquel momento, a un ritmo más acelerado que las disponibilidades; pero téngase presente que es'a situación es frecuente cuando en la confección y desarrollo de los. presupuestos no se tienen en cuenta las prescripciones técnicas necesarias, computando los ingresos por encima de su tendimiento normal, apurando las cifras de gastos más allá del límite de una prudente economía y, en fin, autorizando transferencias de créditos cuando los ingresos no alcanzan las cifras autorizadas a consecuencia de una disminución de la recaudación. En este caso ol problema no se resurlve; pues. en definitiva, se está ante un déficil presupues'ario y el préstamo concedido no hace otra cosa que diferir las conseruencias de este déficit al final del ejercicio, en cuyo momento las Atcas locales estarán exhaustas como en el momento de la petición del préstamo y, por tanto, es menester tenerlo presente en el nuevo presupuesto a confeccionar con perjuicio de los servicios y con aumento de los intereses a pagar.

Estas operaciones se registran en Contabilidad en forma parecida a las an'eriores. Se abritán dos cuentas, una en Ingresos, capítulo Fondos Independ:entes del Presupuesto, artículo Operaciones del Tesoro, concepto Préstamos; y otra en Gastos, el mismo capitulo y artículo, concepto Devo982 lución de Préstamos. Al ser concedido el préstamo se expedirá un carga- 
réme al capíulo, artículo y concepto indicados, y al devolverio se expedirá un lib:amiento con cargo a la expresada cuenta; los pagos efectuados utilizando el préstamo concedido se cargarán a los capítulos y artículos correspondientes del Presupuesto; los intereses del préstamo se pagarán con cargo a Imprevistos si no hulsiera partida especifica en los Presupuestos. La cuenta de Présiamos es de activo, se carga de los préstamos al acordar su petición y se data al efectuar el ingreso como contrapartida del cargaréme sentado en el Diario de Intervenc:ón de Pagos, columna Fondos In-dependin'es del Presupusto. Si las operaciones fueran numerosas, se abrirá un Auxiliar a las diferentes partidas o acreedores, cuya data, será la data de la cuenta de Préstamos y cuyo cargo, será el cargo de la cuenta Devoluciones de Préstamo.

El sistema de registro preconizado en este estudio se somete al rigorismo científico y, por tanto, difiere del empleado por el Estado que, con su método empírico, sc aparta de los principios de la Ciencia, a pesar de los trabajos llevados a cabo por distinguidos compañeros del Cuerpo pericia! de Contabilidad. Las mutaciones del conjunto "Deudores del Tesoro" se desdoblan en dos cuentas, "Anticipos" y "Reembolsos", las cuales funcionan a base del contraido de la operación representada por cada una y así la primera es de pasivo, ya que, una vez acordado el ani icipo, es obligado pagarlo, y la segunda es de activo porque, acordado el reembolso, existe el derecho de ingresarlo. Al pasar al Auxiliar las partidas de las cuentas principales ya no es menester el contraido exigido en la Contabilidad Financiera y vuelven a unirse los dos conceptos de Deudores del Tesoro formando una sola cuenta de Con abil:dad Patrimonial, cuyo significado es de crédito o de activo, tal como funciona el Auxiliar de Operaciones del Tesoro llevado por el Estado, donde se da el contrasentido cientifico de operar con un Auxiliar careciendo de las cuentas principales que le dan vida. Parecidas observaciones se pueden hacer en Acreedores del Tesoro.

Confiamos en que estas líneas den solucićn a los múltiples problemas que a d:ario se presentan en las Haciendas Locales; si cllo es asi, habremos contribuído a establecer la norma juridica que, manejada con prudencia, nos dará el instrumento necesario para una ordenación de la Tesorería en las Corporaciones Locales.

Julio Blanco Lopez

Interventor del Ayuntamiento de Gijon 